\title{
Oceanographic features and limited dispersal shape the population genetic structure of the vase sponge Ircinia campana in the Greater Caribbean
}

\author{
Sarah M. Griffiths $\mathbb{D}^{1} \cdot$ Mark J. Butler IV ${ }^{2}$ Donald C. Behringer $\mathbb{B}^{3,4} \cdot$ Thierry Pérez $^{5} \cdot$ Richard F. Preziosi $^{1}$
}

Received: 23 August 2019 / Revised: 13 July 2020 / Accepted: 13 July 2020 / Published online: 22 July 2020

(c) The Author(s) 2020. This article is published with open access

\begin{abstract}
Understanding population genetic structure can help us to infer dispersal patterns, predict population resilience and design effective management strategies. For sessile species with limited dispersal, this is especially pertinent because genetic diversity and connectivity are key aspects of their resilience to environmental stressors. Here, we describe the population structure of Ircinia campana, a common Caribbean sponge subject to mass mortalities and disease. Microsatellites were used to genotype 440 individuals from 19 sites throughout the Greater Caribbean. We found strong genetic structure across the region, and significant isolation by distance across the Lesser Antilles, highlighting the influence of limited larval dispersal. We also observed spatial genetic structure patterns congruent with oceanography. This includes evidence of connectivity between sponges in the Florida Keys and the southeast coast of the United States ( $>700 \mathrm{~km}$ away) where the oceanographic environment is dominated by the strong Florida Current. Conversely, the population in southern Belize was strongly differentiated from all other sites, consistent with the presence of dispersal-limiting oceanographic features, including the Gulf of Honduras gyre. At smaller spatial scales $(<100 \mathrm{~km})$, sites showed heterogeneous patterns of low-level but significant genetic differentiation (chaotic genetic patchiness), indicative of temporal variability in recruitment or local selective pressures. Genetic diversity was similar across sites, but there was evidence of a genetic bottleneck at one site in Florida where past mass mortalities have occurred. These findings underscore the relationship between regional oceanography and weak larval dispersal in explaining population genetic patterns, and could inform conservation management of the species.
\end{abstract}

Associate editor: Rui Faria

Supplementary information The online version of this article (https:// doi.org/10.1038/s41437-020-0344-6) contains supplementary material, which is available to authorized users.

Sarah M. Griffiths

sarah.griffiths@mmu.ac.uk

1 Ecology and Environment Research Centre, Manchester Metropolitan University, Manchester, UK

2 Department of Biological Sciences, Institute of Environment, Florida International University, North Miami, FL, USA

3 Fisheries and Aquatic Sciences, University of Florida, Gainesville, FL, USA

4 Emerging Pathogens Institute, University of Florida, Gainesville, FL, USA

5 Institut Méditerranéen de Biodiversité et d'Ecologie Marine et Continentale, Aix Marseille Université, Marseille, France

\section{Introduction}

The spatial distribution of genetic diversity is influenced by both ecological and evolutionary processes, and can be used to infer a number of important characteristics of species, including dispersal, recruitment and gene flow among populations (connectivity). Understanding these processes can help in ecosystem management and conservation (Baums 2008; Almany et al. 2009). In addition, identifying changes in genetic diversity, population bottlenecks and inbreeding is vital in the face of declining populations and environmental change, given their effects on population resilience, adaptive potential and fitness.

In Greater Caribbean marine ecosystems, sponges are abundant, diverse and serve important ecological functions, including cycling of organic material and habitat provisioning (Diaz and Rutzler 2001; Bell et al. 2014; Valentine and Butler 2019). Sponges form a major component of the benthos in many coral reef ecosystems, and can dominate in shallow hard-bottom lagoons (Bertelsen et al. 2009). 
Despite their prominence and importance, relatively little is known about population structure in Caribbean sponges. Furthermore, in some localities, sponges have suffered mass mortality events (Butler et al. 1995; Wulff 2006), including in the Florida Keys, where recurring die-offs of the sponge community have had numerous negative consequences for associated communities (Butler et al. 1995, 2016; Herrnkind et al. 1997). Increasing our knowledge of the factors driving population structure in sponges is important in understanding their recruitment and dispersal patterns, and may be important for creating ecosystem-based management plans for the region.

In marine systems, population genetic structure is shaped by a dynamic interplay between life history, oceanographic features and demographic stochasticity (Knutsen et al. 2003; Hoffman et al. 2011). As sponges are sessile for the majority of their life cycle, dispersal at the larval stage is crucial in shaping their population structure. The larval phase is generally very short in sponges, ranging from a few hours to a few days (Maldonado and Riesgo 2008), suggesting that philopatry should be high (with a few known exceptions in the hoplitomella larvae; Vacelet 1999). This life history mode can result in more fragmented and isolated populations, as it limits dispersal and thus connectivity among populations (Shanks 2009). However, ocean currents can potentially increase connectivity among distant locations (Chaves-Fonnegra et al. 2015; Richards et al. 2016). Furthermore, strong wave action, predation and discards from commercial sponge fishing produce fragments, which may disperse before reattaching to the substrate (Wulff 1991; Maldonado and Uriz 1999; Butler et al. 2017). However, temporal variation in ocean circulation, as well as demographic stochasticity, can yield unpredictable and chaotic patterns of population structure (Siegel et al. 2008; Castorani et al. 2017; Drury et al. 2018).

To date, empirical population genetics studies have been conducted on only four Caribbean sponge species (Xestospongia muta: López-Legentil and Pawlik 2009; de Bakker et al. 2016; Richards et al. 2016; Callyspongia vaginalis: DeBiasse et al. 2010; Cliona delitrix: Chaves-Fonnegra et al. 2015; Spheciospongia vesparium: Griffiths et al. 2020). In general, these studies have found strongly differentiated populations throughout the region, including among sites only tens of kilometres apart in some instances. However, patterns of regional genetic structure often reflect major ocean currents and hydrology (López-Legentil and Pawlik 2009; ChavesFonnegra et al. 2015; Richards et al. 2016; Griffiths et al. 2020), and evidence of long-distance dispersal has been found, suggesting irregular transport of larvae, gametes or sponge fragments in ocean currents over large oceanographic distances (DeBiasse et al. 2010; Chaves-Fonnegra et al. 2015). These studies reveal the complexities of sponge population genetics in the Caribbean, highlighting the need for further research on this understudied taxon, including locations that have not yet been sampled.

In this study, we explore population genetic structure in the Caribbean vase sponge Ircinia campana (Lamarck 1814), a common species in coral reef and hard-bottom habitats. The reproduction and larval biology of I. campana has not yet been described; however, other Ircinia species are viviparous, with no true asexual reproduction (through budding or gemmules), and the vase-shaped morphology of I. campana is not susceptible to fragmentation during storms. This species is prone to disease outbreaks, and has suffered a number of mass mortality events, the most extensive having occurred in the Florida Keys (Butler et al. 1995). Due to both its prevalence in the region's benthic communities and its apparent vulnerability, it is important to understand the genetic diversity and structure of I. campana in the Greater Caribbean. Here, we aimed to describe the population structure of I. campana and explore the effects of mass mortalities on genetic diversity.

\section{Materials and methods}

\section{Sampling}

We sampled 10-41 I. campana individuals at 19 sites throughout the Greater Caribbean (Table 1and Fig. 1) from depths of 1-25 m, resulting in a total sample size of 440 individual sponges. Sponge communities, including I. campana, at two of the sampling sites (Bamboo Key and Long Key in the Florida Keys) have previously been affected by mass mortalities associated with cyanobacterial blooms. We cut small fragments of tissue $\left(\sim 1.5 \mathrm{~cm}^{3}\right)$ and preserved them in $95 \%$ ethanol soon after surfacing. Ethanol was replaced after $24 \mathrm{~h}$ to avoid dilution with the seawater held in the sponge tissue.

\section{Microsatellite genotyping}

We dissected samples under a stereomicroscope to remove macroinvertebrates from the sponge tissue, and extracted DNA using the DNeasy ${ }^{\circledR}$ Blood and Tissue Kit (Qiagen). We genotyped the samples for 10 microsatellite loci, as described in Griffiths et al. (2019). Briefly, we amplified the loci in two multiplex PCR reactions (Griffiths et al. 2019) with the Typeit Microsatellite PCR Kit (Qiagen), using the following thermal cycling conditions: initial denaturation of $95^{\circ} \mathrm{C}$ for 5 min, 28 cycles of $95^{\circ} \mathrm{C}$ for $30 \mathrm{~s}, 60^{\circ} \mathrm{C}$ (Multiplex A) or $63{ }^{\circ} \mathrm{C}$ (Multiplex B) for $90 \mathrm{~s}$ and $72{ }^{\circ} \mathrm{C}$ for $30 \mathrm{~s}$, followed by a final extension of $60^{\circ} \mathrm{C}$ for $30 \mathrm{~min}$. Alleles were then sized using capillary electrophoresis on a DNA Analyzer 3730 (Thermo Fisher Scientific), and scored using Genemapper 
Table 1 Ircinia campana sampling locations.

\begin{tabular}{|c|c|c|c|c|c|}
\hline Location & Site name & Site code & $n$ & Latitude, longitude & Date $(\mathrm{M} / \mathrm{YY})$ \\
\hline Gray's Reef National Marine Sanctuary, Georgia, USA & Gray's Reef & GR & 10 & $31.40480,-80.86677$ & $6 / 13$ \\
\hline Long Key, Florida Keys, USA & Long Key & LK & 20 & $24.81437,-80.83073$ & $7 / 14$ \\
\hline Bamboo Key, Florida Keys, USA & Bamboo Key & BK & 16 & $24.74429,-80.99504$ & $7 / 14$ \\
\hline Kemp Channel, Florida Keys, USA & Kemp Channel & $\mathrm{KC}$ & 20 & $24.67687,-81.47577$ & $7 / 14$ \\
\hline Waltz Key, Florida Keys, USA & Waltz Key & WK & 17 & $24.65108,-81.65213$ & $7 / 14$ \\
\hline Boca Chica Channel, Florida Keys, USA & Boca Chica Channel & $\mathrm{BC}$ & 18 & $24.60495,-81.71508$ & $7 / 14$ \\
\hline Lakes Passage, Florida Keys, USA & Lakes Passage & LP & 20 & $24.56948,-81.87572$ & $7 / 14$ \\
\hline Turneffe Atoll, Belize & Turneffe Atoll & TA & 35 & $17.54436,-87.82664$ & $4 / 13$ \\
\hline Tom Owen's Caye, Sapodilla Cayes, Belize & Sapodilla Cayes & $\mathrm{SC}$ & 39 & $16.18898,-88.23277$ & $4 / 13$ \\
\hline Bocas Del Toro (1), Panama & Panama 1 & PAN1 & 15 & $9.32833,-82.22668$ & $7 / 16$ \\
\hline Bocas Del Toro (2), Panama & Panama 2 & PAN2 & 16 & $9.30604,-82.23275$ & $7 / 16$ \\
\hline Bocas Del Toro (3), Panama & Panama 3 & PAN3 & 11 & $9.2413,-82.1737$ & $7 / 16$ \\
\hline Mayreau, St. Vincent and The Grenadines & Mayreau & MAY & 20 & $12.64218,-61.37975$ & $5 / 15$ \\
\hline Bequia, St. Vincent and The Grenadines & Bequia & BEQ & 27 & $12.99128,-61.29043$ & $5 / 15$ \\
\hline St. Vincent, St. Vincent and The Grenadines & St. Vincent & STV & 40 & $13.18303,-61.26945$ & $5 / 15$ \\
\hline Anse Chastenet, St. Lucia & St. Lucia & STL & 41 & $13.86413,-61.07882$ & $5 / 15$ \\
\hline Grande Anse d'Arlet, Martinique & Martinique 1 & MAR1 & 17 & $14.5059,-61.0932$ & $5 / 15$ \\
\hline Diamond Rock, Martinique & Martinique 2 & MAR2 & 26 & $14.4426,-61.04013$ & $5 / 15$ \\
\hline Port-Louis, Grande-Terre, Guadeloupe & Guadeloupe & GU & 32 & $16.46233,-61.53062$ & $5 / 15$ \\
\hline
\end{tabular}

$n$ number of individuals successfully genotyped.

v3.7 (Thermo Fisher Scientific). All plates for PCR and genotyping contained positive and negative controls.

\section{Quality control and summary statistics}

We tested linkage disequilibrium between loci using Genepop on the Web v4.2 (Raymond and Rousset 1995), and corrected significance for multiple tests (Benjamini and Yekutieli 2001; $\mathrm{B}-\mathrm{Y}$ correction) using the p.adjust function in $\mathrm{R} 3.4 .3$ ( $\mathrm{R}$ Core Team 2017). We calculated null allele frequencies in FreeNA (Chapuis and Estoup 2007) using the Expectation Maximisation algorithm (Dempster et al. 1977), and then conducted a post hoc analysis to determine the influence of null alleles on population differentiation estimation. This analysis was carried out by calculating global $F_{\mathrm{ST}}$ with and without correction for null alleles using the ENA method of Chapuis and Estoup (2007). Following this, the locus with the highest null allele frequency was removed, and $F_{\mathrm{ST}}$ with and without ENA correction was recalculated (sensu ChavesFonnegra et al. 2015). This was repeated sequentially until only one locus remained. This analysis revealed that the two loci with the highest null allele frequencies, Icam34 and Icam10, skewed uncorrected global $F_{\mathrm{ST}}$ estimates over 0.01 (Table S1). Consequently, in analyses where correction for null alleles could be implemented $\left(F_{\mathrm{ST}}\right.$ and populationaverage inbreeding coefficient $\left(F_{\mathrm{IS}}\right)$ calculations), the full tenloci dataset was used. In all other analyses, Icam34 and Icam10 were excluded, yielding an eight-loci dataset.
We calculated probability of deviation from Hardy-Weinberg equilibrium (HWE), observed heterozygosity $\left(H_{\mathrm{O}}\right)$ and Nei's gene diversity $\left(H_{\mathrm{S}}\right)$ (expected heterozygosity) for each sampling site using GenoDive v2.0b23 (Meirmans and Van Tienderen 2004). We calculated the average $F_{\text {IS }}$ for each site corrected for null alleles in INEst v2.1 (Chybicki and Burczyk 2009), which uses a likelihood-based method to estimate $F_{\mathrm{IS}}$ and null allele frequencies simultaneously. We used the Interacting Multiple Model with 500,000 Markov chain Monte Carlo (MCMC) cycles and 50,000 burn-in cycles. We ran the model using all combinations of parameters for possible null allele causes ('n': null alleles; 'b': genotyping failure; ' $\mathrm{f}$ ': inbreeding), and used Bayesian deviance information criterion (DIC) to infer which parameters contributed more to the observed data.

\section{Genetic diversity and bottlenecks}

We assessed genetic diversity of the sites using ADZE (Szpiech et al. 2008), which uses a rarefaction method to calculate allelic richness and private allelic richness corrected for sample size variation. Gray's Reef was excluded from this analysis due to its small sample size, and because the marker Icam 3 did not amplify in any sample from this site. We used linear mixed models to test for differences in genetic diversity between sites, with site as a fixed effect, and locus as a random effect due to inter-marker variation in 


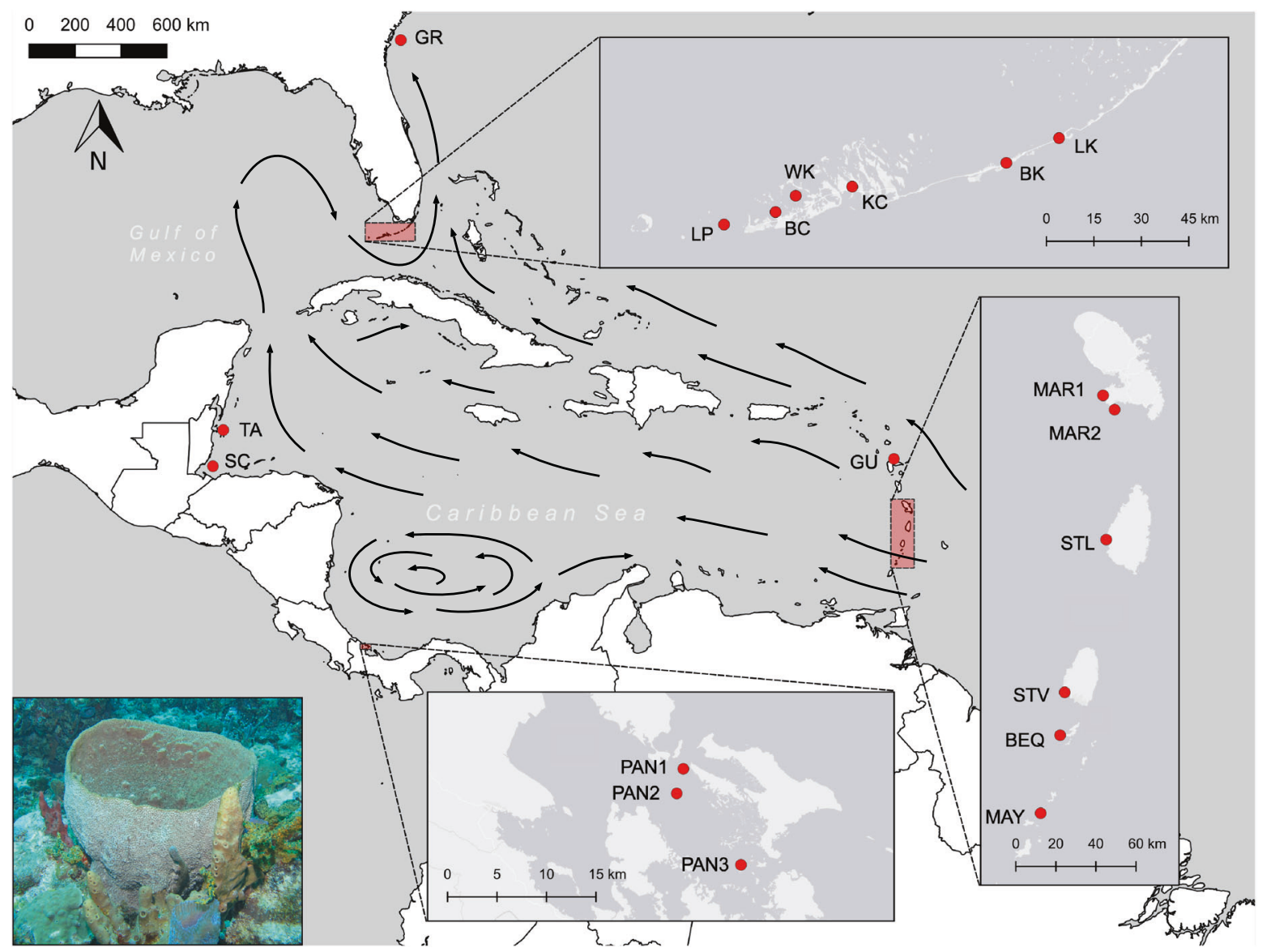

Fig. 1 Map showing Ircinia campana sampling locations. GR Gray's Reef, LK Long Key, BK Bamboo Key, KC Kemp Channel, WK Waltz Key, BC Boca Chica Channel, LP Lakes Passage, TA Turneffe Atoll, SC Sapodilla Cayes, PAN1 Panama 1, PAN2 Panama 2, PAN3 Panama 3, MAY Mayreau, BEQ Bequia, STV St. Vincent,

diversity (Soro et al. 2017; Maebe et al. 2018). We tested both rarefied allelic richness and $H_{\mathrm{S}}$ in separate models (eight-loci datasets), and ran the models using the R package 'Ime4' (Bates et al. 2015). We used likelihood ratio tests to compare these models against their respective null models (i.e., excluding the fixed effect factor 'site'). When significantly different, we ran a post hoc Tukey test to determine which sites significantly differed using the glht function in the R package 'multcomp' (Hothorn et al. 2008).

We tested for genetic signatures of bottlenecks at each sampling site by testing for significant heterozygosity excess in relation to allelic richness (Piry et al. 1999), as implemented in INEst v2.1. In bottleneck events, both heterozygosity and the number of alleles reduce; however, the allelic richness declines faster than heterozygosity, resulting in heterozygosity excess. We ran the two-phase mutation model with the proportion of multistep mutations set as 0.22 , and the average multistep mutation size as 3.1, as recommended by Chybicki and Burczyk (2009). We ran the model using 100,000 coalescent simulations, and tested
STL St. Lucia, MAR1 Martinique 1, MAR2 Martinique 2, GU Guadeloupe. Inset (bottom left): Ircinia campana photographed in Bequia (T. Pérez). Arrows show major ocean current patterns in the Caribbean Sea. Basemaps: ESRI, Natural Earth.

significance using the Wilcoxon signed-rank test, calculated based on 1,000,000 permutations.

\section{Population structure analysis}

The traditional measure of subpopulation differentiation, $F_{\mathrm{ST}}$, can underestimate differentiation when variation in markers is high (Jost 2008). Because high numbers of alleles were present in a number of loci in our samples (up to 97 alleles per locus, Table S2), we also used Jost's $D$ to estimate population differentiation (Jost 2008). We calculated population pairwise $D$ and $F_{\mathrm{ST}}$ in GenoDive using the eight-loci dataset (referred to as $D$ and $F_{\mathrm{ST}(8)}$ hereafter), and tested significance using 50,000 permutations (with $\mathrm{B}-\mathrm{Y}$ correction applied for multiple tests). We also calculated $F_{\mathrm{ST}}$ between population pairs for all ten loci with ENA correction for null alleles in FreeNA (referred to as $F_{\mathrm{ST}(10)}$ hereafter). We tested correlation between matrices of $F_{\mathrm{ST}(8)}, F_{\mathrm{ST}(10)}$ and $D$, using Mantel tests in the 'ade4' package in $\mathrm{R}$ with 9999 permutations. 
To visualise genetic distance relationships among sites, we carried out principal coordinate analysis (PCoA) in GenAlEx 6.503 (Peakall and Smouse 2012) using standardised covariance matrices of population pairwise $D$.

We tested for the presence of genetic isolation-bydistance (IBD) patterns in the data by testing the correlation between pairwise matrices of linearised genetic distances $\left(F_{\mathrm{ST}(10)} / 1-F_{\mathrm{ST}(10)}\right.$ and $\left.D / 1-D\right)$ and the logarithm of oceanographic distances with Mantel tests in 'ade4' in R, using 9999 permutations. We calculated least-cost oceanographic distances among sites (i.e., the shortest path, excluding landmasses) using 'marmap' in R (Pante and Simon-Bouhet 2013). We conducted these tests within the Lesser Antilles (Guadeloupe, Martinique, St. Lucia, St. Vincent, Bequia and Mayreau) and within the Florida Keys.

We used a spatially explicit Bayesian approach implemented in 'Geneland' v4.0.6 in R (Guillot et al. 2008) to identify the number of population clusters $(K)$ and individual assignment probabilities to those clusters, using the eight-loci dataset. We first ran the model using the uncorrelated allele frequencies, spatial and null allele models with 1,000,000 iterations, 100 thinning and 500 burn-in. According to the authors' advice, we set the maximum number of nuclei to $1320(3 \times$ sample size $)$ and the maximum rate of the Poisson process to $440(1 \times$ sample size $)$, and the spatial uncertainty on coordinates to 0.0005 . We carried out ten independent runs of $K$ from 1 to 19 , and checked that clusters were consistent among runs. We then selected the run with the highest posterior probability to estimate allele frequencies and cluster locations to use subsequently in the admixture model. We ran the admixture model using the same parameters as above, and extracted the Q matrix of individual probability assignments to each cluster to build a bar plot in Distruct (Rosenberg 2004). We repeated the analysis on each identified cluster to test for the presence of substructure in a hierarchical clustering approach sensu Vaha et al. (2007), modifying the maximum number of nuclei and the maximum rate of the Poisson process according to the number of samples in the data subsets.

We carried out Discriminant Analysis of Principal Components (DAPC) (Jombart et al. 2010) using 'adegenet' (v2.0.1) (Jombart 2008) in R. This method uses Principal Component Analysis to transform the data, and then uses the retained principal components in Discriminant Analysis. This is effective in minimising within-group genetic variation and maximising between-group variation, and does not make assumptions regarding HWE in populations. The number of principal components retained varied among analyses; if too many are retained, the resulting membership probabilities can be unstable. We therefore retained the maximum number possible without compromising stability (displayed graphically in each DAPC plot). As before, we repeated the analysis for each multisite cluster identified.

\section{Results}

\section{Summary statistics, HWE and $\boldsymbol{F}_{\mathrm{IS}}$}

All loci were in linkage equilibrium after $\mathrm{B}-\mathrm{Y}$ correction ( $p>0.05$ ). Two identical multilocus genotypes (i.e., clones) were present in the dataset (both individuals from Turneffe Atoll), one of which was removed for subsequent analyses. Average null allele frequencies were high at many loci, overall ranging from $<0.001$ (Icam32) to 0.323 (Icam34) (Table S2). Loci were highly polymorphic, with the total number of alleles per locus ranging from 4 to 97 (Table S2).

There were significant departures from HWE $(p<0.05)$ at a number of loci and sites following the correction for multiple tests (Table S3). Null allele-corrected average $F_{\text {IS }}$ values were all positive, ranging from 0.033 in Panama 2 to 0.450 in Bamboo Key, Florida (Table 2); however, posterior $95 \%$ probability intervals included zero for all sites but Bamboo Key. Model comparison using DIC values revealed that null alleles were important in affecting $F_{\text {IS }}$ estimates in all sites, along with genotyping failure and/or inbreeding in some of the populations (Tables 2 and S4).

\section{Genetic diversity and bottlenecks}

$H_{\mathrm{O}}$ ranged from 0.305 (Kemp Channel) to 0.565 (Panama C) within sites, and $H_{\mathrm{S}}$ ranged from 0.528 (Gray's Reef) to 0.761 (Mayreau) (Table 2). The linear mixed model showed that site had no significant effect on $H_{\mathrm{S}}$; however, the $p$ value was marginal $\left(X^{2}=28.315, p=0.057\right)$. Rarefied allelic richness per site ranged from $3.258 \pm 0.552 \mathrm{SE}$ (Waltz Key) to $4.667 \pm 0.589$ SE (Mayreau) (Table 2 and Fig. S1). Site had a significant effect on rarefied allelic richness according to the linear mixed model $\left(X^{2}=40.695\right.$, $p=0.001)$. However, post hoc Tukey tests revealed that only three pairs of sites were significantly different: allelic richness was significantly higher at St. Lucia than at Turneffe Atoll $(z=-4.494, p=0.049)$, at Mayreau than at Turneffe Atoll $(z=-3.859, p=0.013)$ and at Mayreau than at Waltz Key $(z=-3.738, p=0.022)$. All other siteby-site comparisons were not significant $(p>0.05)$, although three comparisons were close to significance (higher allelic richness at St. Lucia than at Waltz Key: $z=-3.373, \quad p=0.072$, at Bequia than at Turneffe Atoll: $z=-3.421, p=0.062$ and at Bequia than at Waltz Key: $z=-3.300, p=0.083)$. Rarefied private allelic richness ranged from $0.237 \pm 0.107$ (Waltz Key) to $1.302 \pm$ 0.432 (St. Lucia) (Table 2 and Fig. S1).

Significant heterozygosity excess with respect to allelic richness was detected only at Bamboo Key $(p=0.014)$, indicative of a genetic bottleneck. 
Table 2 Genetic diversity and average inbreeding coefficient in Ircinia campana per location.

\begin{tabular}{|c|c|c|c|c|c|c|c|c|c|}
\hline Site name & Site code & $H_{\mathrm{O}(8)}$ & $H_{\mathrm{E}(8)}$ & $\operatorname{Av} F_{\text {IS }}$ & Model & 95\% HPDI & AR & $\mathrm{rAR} \pm \mathrm{SE}$ & $\mathrm{rPAR} \pm \mathrm{SE}$ \\
\hline Gray's Reef & GR & 0.325 & 0.528 & 0.037 & $\mathrm{nb}$ & $0-0.131$ & 3.8 & - & - \\
\hline Long Key & LK & 0.414 & 0.665 & 0.149 & $\mathrm{nb}$ & $0-0.339$ & 8.6 & $4.319 \pm 0.651$ & $0.917 \pm 0.289$ \\
\hline Bamboo Key & BK & 0.365 & 0.643 & 0.450 & $\mathrm{nfb}$ & $0.122-0.668$ & 6.0 & $3.920 \pm 0.556$ & $0.675 \pm 0.201$ \\
\hline Kemp Channel & $\mathrm{KC}$ & 0.305 & 0.578 & 0.099 & $\mathrm{n}$ & $0-0.291$ & 7.3 & $3.635 \pm 0.659$ & $0.523 \pm 0.219$ \\
\hline Waltz Key & WK & 0.317 & 0.557 & 0.226 & $\mathrm{nf}$ & $0-0.416$ & 5.3 & $3.258 \pm 0.552$ & $0.237 \pm 0.107$ \\
\hline Boca Chica Channel & $\mathrm{BC}$ & 0.377 & 0.65 & 0.148 & $\mathrm{nb}$ & $0-0.371$ & 6.7 & $4.048 \pm 0.597$ & $0.750 \pm 0.243$ \\
\hline Lakes Passage & LP & 0.365 & 0.644 & 0.092 & $\mathrm{nb}$ & $0-0.272$ & 6.9 & $3.809 \pm 0.556$ & $0.758 \pm 0.269$ \\
\hline Turneffe Atoll & TA & 0.397 & 0.603 & 0.047 & $\mathrm{nf}$ & $0-0.117$ & 6.5 & $3.321 \pm 0.446$ & $0.533 \pm 0.289$ \\
\hline Sapodilla Cayes & $\mathrm{SC}$ & 0.516 & 0.725 & 0.068 & $\mathrm{nfb}$ & $0-0.142$ & 9.6 & $4.112 \pm 0.384$ & $1.215 \pm 0.236$ \\
\hline Panama 1 & PAN1 & 0.509 & 0.634 & 0.077 & $\mathrm{nb}$ & $0-0.229$ & 5.9 & $3.505 \pm 0.541$ & $0.554 \pm 0.228$ \\
\hline Panama 2 & PAN2 & 0.565 & 0.695 & 0.033 & $\mathrm{nb}$ & $0-0.111$ & 5.6 & $3.656 \pm 0.413$ & $0.569 \pm 0.236$ \\
\hline Panama 3 & PAN3 & 0.466 & 0.661 & 0.057 & $\mathrm{nb}$ & $0-0.167$ & 4.8 & $3.580 \pm 0.503$ & $0.602 \pm 0.213$ \\
\hline Mayreau & MAY & 0.535 & 0.761 & 0.159 & $\mathrm{nfb}$ & $0-0.304$ & 9.9 & $4.667 \pm 0.589$ & $1.229 \pm 0.362$ \\
\hline Bequia & BEQ & 0.496 & 0.692 & 0.093 & $\mathrm{nb}$ & $0-0.237$ & 11.8 & $4.627 \pm 0.612$ & $0.926 \pm 0.274$ \\
\hline St. Vincent & STV & 0.457 & 0.654 & 0.034 & $\mathrm{nb}$ & $0-0.104$ & 13.1 & $4.502 \pm 0.662$ & $1.135 \pm 0.370$ \\
\hline St. Lucia & STL & 0.473 & 0.740 & 0.075 & $\mathrm{nb}$ & $0-0.195$ & 13.0 & $4.585 \pm 0.583$ & $1.302 \pm 0.432$ \\
\hline Martinique 1 & MAR1 & 0.495 & 0.687 & 0.102 & $\mathrm{n}$ & $0-0.251$ & 7.8 & $4.380 \pm 0.589$ & $0.891 \pm 0.286$ \\
\hline Martinique 2 & MAR2 & 0.502 & 0.627 & 0.048 & $\mathrm{n}$ & $0-0.135$ & 8.7 & $4.027 \pm 0.562$ & $0.939 \pm 0.281$ \\
\hline Guadeloupe & GU & 0.368 & 0.642 & 0.086 & $\mathrm{n}$ & $0-0.242$ & 10.1 & $4.071 \pm 0.621$ & $1.212 \pm 0.379$ \\
\hline
\end{tabular}

$H_{\mathrm{O}(8)}$ observed heterozygosity (over eight loci), $H_{\mathrm{E}(8)}$ expected heterozygosity (over eight loci), $A v F_{\mathrm{IS}}$ average inbreeding coefficient corrected for null alleles, Model model with lowest deviance information criteria for estimating the inbreeding coefficient in the presence of combinations of null alleles (n), inbreeding (f) and genotyping failure (b), 95\% HPDI 95\% highest posterior density interval for Av $F_{\text {IS }}$ calculation, $A R$ average allelic richness, $r A R \pm S E$ average rarefied allelic richness over ten loci ( \pm standard error of the mean), maximum standardised sample size (max $\mathrm{g}$ ) $=8$, $r P A R \pm S E$ average rarefied private allelic richness over ten loci ( \pm standard error of the mean), maximum standardised sample size $($ max $\mathrm{g})=8$.

\section{Population structure}

Our analyses showed strong population structure across the region, with $F_{\mathrm{ST}(10)}$ reaching 0.233 (between Gray's Reef and Panama 1) and $D$ reaching 0.598 (between Gray's Reef and Sapodilla Cayes) (Tables S5 and S6). The genetic distance measures were strongly correlated $\left(F_{\mathrm{ST}(10)}\right.$ and $F_{\mathrm{ST}(8)}: r=0.921, p<0.001 ; F_{\mathrm{ST}(8)}$ and $D: r=0.908, p<$ $0.001 ; F_{\mathrm{ST}(10)}$ and $\left.D: r=0.825, p<0.001\right)$.

IBD was significant within the Lesser Antilles subset (pairwise distances $15-443 \mathrm{~km} ; F_{\mathrm{ST}(10)} r=0.793, p=$ 0.001; $D: r=0.688, p<0.001$ ) (Fig. 2a) but not within the Florida subset (pairwise distances $10-115 \mathrm{~km} ; F_{\mathrm{ST}(10)}: p=$ 0.483; $D: p=0.476$ ) (Fig. 2b).

Geneland analysis of the whole dataset identified four genetic clusters (Fig. 3a), with further population structure identified on subsequent hierarchical analysis of the original clusters. Clusters were composed as follows: (1) all USA sites, (2) the southern Lesser Antilles sites (St. Lucia, St. Vincent, Mayreau and Bequia), (3) the Panama, Turneffe Atoll, Guadeloupe and Martinique sites, and (4) the Sapodilla Caye site in southern Belize alone. Subsequent analysis of multisite clusters identified further substructure between St. Lucia and St. Vincent, Mayreau and Bequia (Fig. 3b), and between Turneffe Atoll, Panama, Martinique and Guadeloupe (Fig. 3c), giving a total of eight clusters over all analyses. The USA sites remained a single cluster.

The DAPC showed a clear separation of the Sapodilla Cayes from all other sites upon analysis of the full dataset
(Fig. 4a). In the subsequent analysis excluding the Sapodilla Cayes, sites formed three clusters (Fig. 4b), comprising (1) all USA sites, (2) St. Vincent, Mayreau, Bequia, St. Lucia and Martinique and (3) Panama, Turneffe Atoll and Guadeloupe (Fig. 4b). DAPC analyses conducted on these clusters revealed further substructure (Fig. 4c-e): Panama, Guadeloupe and Turneffe Atoll separated into individual groups (Fig. 4c); Bequia, Mayreau and St. Vincent clustered together, while St. Lucia, Martinique 1 and Martinique 2 formed separate but closely located clusters (Fig. 4d). In common with other analyses, the USA sites did not separate into multiple clusters, although Lakes Passage was the most differentiated (Fig. 4e).

PCoA plots showed some regional-scale clustering patterns consistent with the Geneland and DAPC analyses (Fig. 5). The first axis represented $25.62 \%$ of the variation in $D$ among sites, the second axis represented $21.02 \%$ and the third axis represented $12.48 \%$, giving a total of $59.12 \%$ over the three axes. The first axis separated the USA sites from the rest of the sites, while the second axis clearly separated a St. Vincent, Mayreau and Bequia cluster (Fig. 5a). The third axis separated the Sapodilla Cayes from all other sites (Fig. 5b).

\section{Discussion}

\section{Departures from HWE and null alleles}

We observed significant deviation from HWE at many loci and sites. There are many potential biological causes of this, 

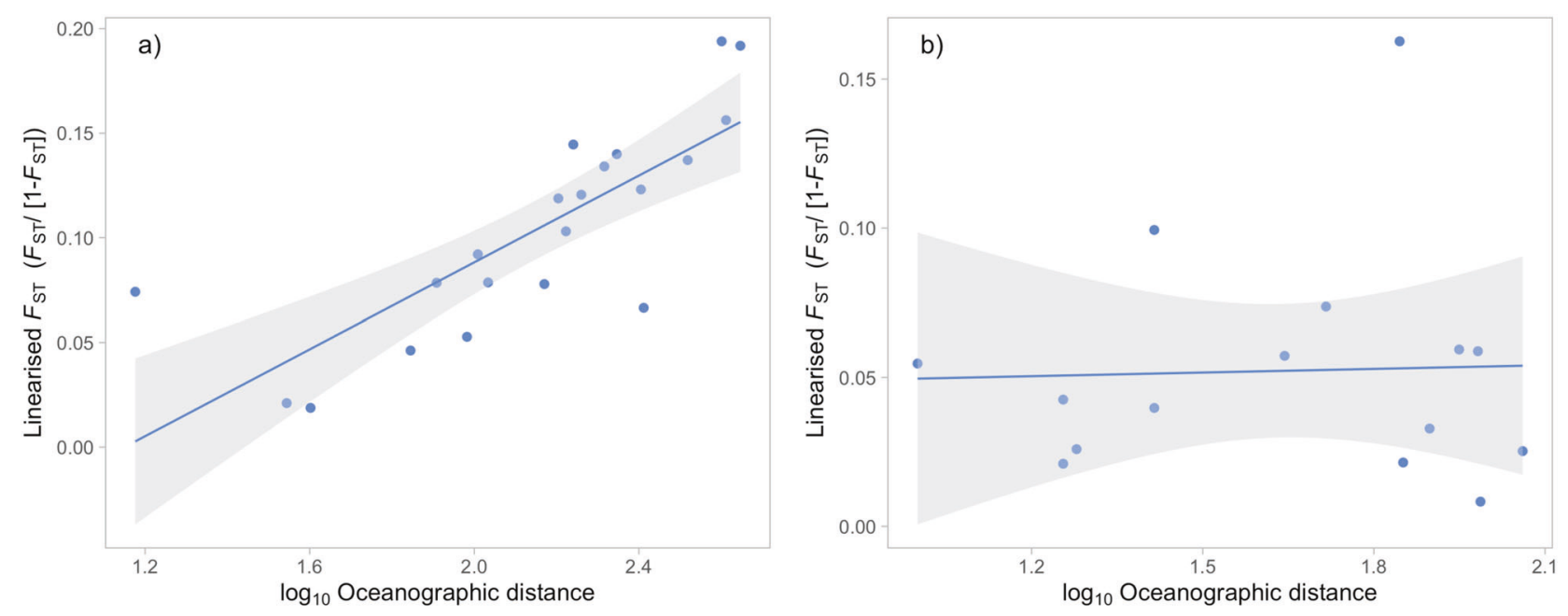

Fig. 2 Genetic isolation by distance in Ircinia campana. Distances displayed are site pairwise linearised $F_{\mathrm{ST}}$ and logarithm of oceanographic distances. (a) Sites within the Lesser Antilles (b) Sites within the Florida Keys.

a

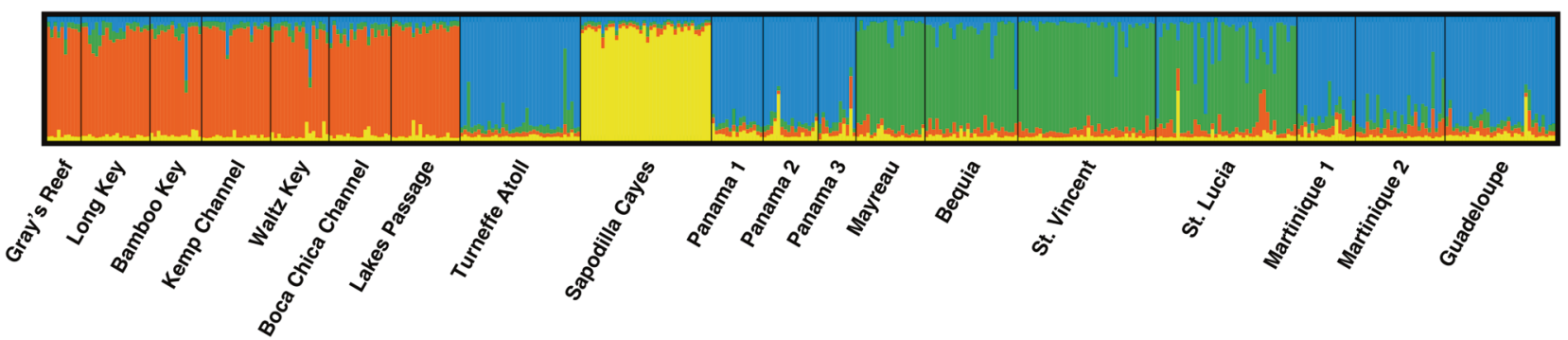

b

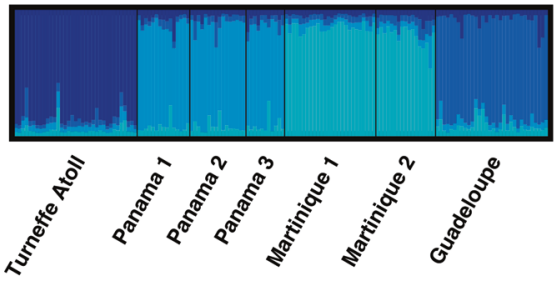

Fig. 3 Geneland plot showing genetic clusters and individual admixture proportions in Ircinia campana. Each bar represents an individual; colours represent genetic cluster identity, and bar heights represent inferred membership proportions to genetic clusters. The analysis was firstly carried out over all sites, showing $K=4$ genetic

including inbreeding, which increases population homozygosity. In sponges, inbreeding could result from low dispersal of planktonic sperm and larvae, which can lead to philopatry and higher incidences of non-random mating.

Another possible cause of HWE departure is genetic structure within a population, or a set of samples, known as the Wahlund effect. In a single geographical site, this could be caused by stochasticity, variation in selective pressures and changes in ocean circulation that alter dispersal patterns over time (Tesson et al. 2014). Although samples were collected
C

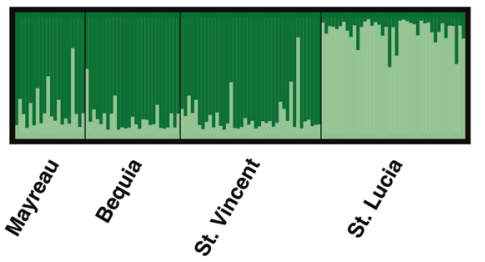

clusters (a); separate analyses were subsequently conducted on multisite clusters identified therein (b, c), showing $K=4(\mathbf{b})$ and $K=2(\mathbf{c})$ genetic clusters. Analysis on the USA cluster yielded $K=1$ (data not shown).

over a 3-year period, we do not believe that this caused temporal structure in our dataset, as sponges are sessile and slow-growing. The high polymorphism of the microsatellite loci used in this study may have also contributed to HWE deviation, as HWE tests are very sensitive to individuals homozygous for rare alleles (Morin et al. 2009).

Deviation from HWE can also be caused by null alleles, which were indeed found at the majority of loci. Null alleles increase estimates of homozygosity, subsequently raising $F_{\text {IS }}$ values. In addition, null alleles can artificially increase 

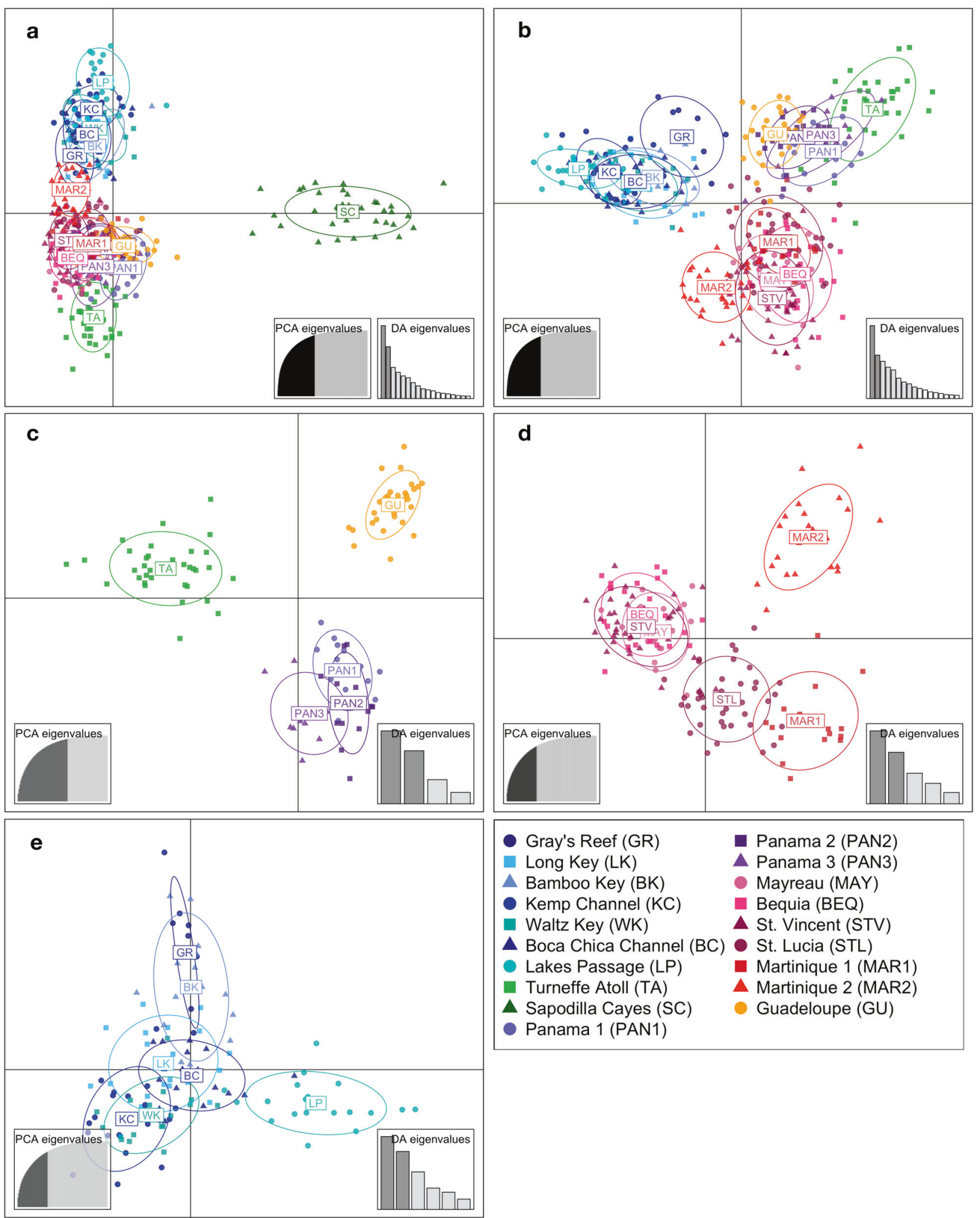

- Gray's Reef (GR)

- Long Key (LK)

$\triangle$ Bamboo Key (BK)

- Kemp Channel (KC)

- Waltz Key (WK)

- Boca Chica Channel (BC)

- Lakes Passage (LP)

- Turneffe Atoll (TA)

- Sapodilla Cayes (SC)

- Panama 1 (PAN1)
Panama 2 (PAN2)

- Panama 3 (PAN3)

- Mayreau (MAY)

Bequia (BEQ)

$\Delta$ St. Vincent (STV)

St. Lucia (STL)

Martinique 1 (MAR1)

$\triangle$ Martinique 2 (MAR2)

- Guadeloupe (GU)
Fig. 4 Discriminant analyses of principal components (DAPC) of Ircinia campana. Individual points represent genotyped individuals; inertia ellipses summarise the point cloud for each site. Sequential analyses were carried out in a hierarchical approach by repeating analyses on clusters detected (a-e). Insets show the proportion of principal component eigenvalues and discriminant analysis eigenvalues retained. 

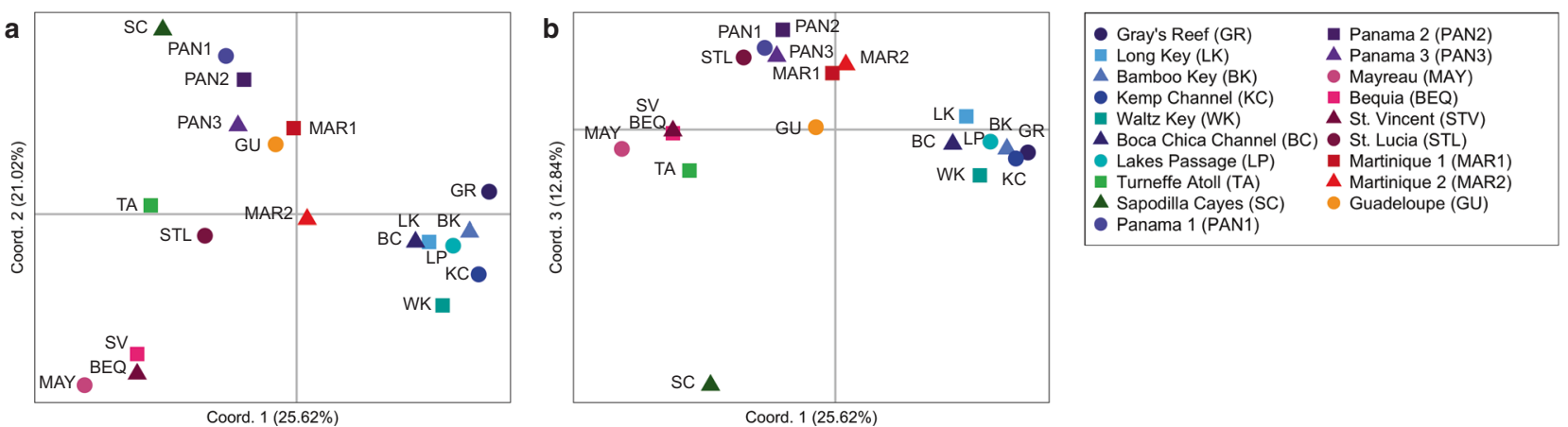

Fig. 5 Principal coordinate analysis (PCoA) of Jost's $D$ genetic distance among Ircinia campana sampling sites. Genetic distances calculated using eight microatellite loci dataset. (a) Axis 1 vs axis 2 (b) axis 1 vs axis 3 .

$F_{\mathrm{ST}}$ values and estimates of population differentiation (Chapuis and Estoup 2007). To mitigate these effects as far as possible, we corrected $F_{\mathrm{ST}}$ values and population-average $F_{\text {IS }}$ values for null alleles, we used the null allele model in Geneland and we excluded the loci that contributed substantially to $F_{\mathrm{ST}}$ skew from other analyses.

Both HWE deviations and null alleles are common in sponge microsatellite studies (Dailianis et al. 2011; ChavesFonnegra et al. 2015; Pérez-Portela et al. 2015; Giles et al. 2015; Guardiola et al. 2016; Richards et al. 2016), suggesting that common life history trends could contribute to these observations. High $F_{\mathrm{IS}}$ and HWE departures are common among marine invertebrates with free-spawned planktonic sperm. Addison and Hart (2005) proposed that this could be associated with higher levels of null alleles, due to higher numbers of cell cycles for sperm production causing increased mutation rates (though sperm production varies interspecifically, and is unknown for I. campana).

\section{Regional-scale population structure}

Our results show the presence of strong regional population structure in I. campana in the Greater Caribbean, with a total of eight to nine genetic clusters identified, indicating highly differentiated populations across the region. This agrees with studies of the Caribbean sponges $C$. delitrix (using microsatellites; Chaves-Fonnegra et al. 2015) and $C$. vaginalis (using mtDNA and nuclear genes; DeBiasse et al. 2016), supporting that the short-lived nature of sponge larvae constrains dispersal, and is an important driver of population structure across the phylum.

The I. campana population in the Sapodilla Cayes was genetically distinct from all other sites according to the DAPC and Geneland analyses. In addition, $D$ values were almost always higher for all population pairwise comparisons involving this site than for any other population pairs. The Sapodilla Cayes is situated in the south of the Mesoamerican Barrier Reef System (MBRS), an area subject to highly retentive oceanographic conditions
(Martínez et al. 2019): a weak southward-flowing coastal current and the anticlockwise Gulf of Honduras Gyre (Ezer et al. 2005; Carrillo et al. 2015), contrasting with the northerly flowing Yucatan Current in the north MBRS. Furthermore, river discharge into the Gulf of Honduras may form an additional barrier to dispersal for stenohaline marine larvae, such as Ircinia spp. (Soto et al. 2009). Genetic studies show population differentiation between the north and south MBRS in the corals Montastrea annularis (Foster et al. 2012) and Orbicella faveolata (Rippe et al. 2017), as well as the neon goby Elacatinus lori (D'Aloia et al. 2017). Genetic evidence also suggests that the lobster Panulirus argus experiences higher selfrecruitment in the south (Truelove et al. 2014). In addition, Muhling et al. (2013) found distinct larval fish assemblages in the north and south MBRS. The breadth of taxa that are affected by this divide, with their varied life histories, supports that ocean circulation is driving differentiation in this area.

The high level of genetic differentiation found at the Sapodilla Cayes in I. campana may be a case of cryptic speciation, as suggested for the neon goby $E$. lori in the same region (D'Aloia et al. 2017). Cryptic species in sponges are common due to absences in morphological variation caused by a lack of complex morphological traits, as well as phenotypic plasticity or convergent evolution resulting in similar morphologies (Sole-Cava et al. 1991; Xavier et al. 2010). However, further studies using phylogenetically informative markers are needed to explore this possibility in I. campana.

Excluding the Sapodilla Cayes, the remaining sites split into three main clusters in both the DAPC and Geneland analyses prior to further hierarchical analyses. The composition of clusters was consistent among analyses, except for the Martinique sites, which clustered with Turneffe Atoll, Panama and Guadeloupe in the Geneland analysis, and with Bequia, Mayreau, St Vincent and St. Lucia in the DAPC. However, cluster-based models are known to not perform as well when genetic variation does not fall into 
discrete groups, but follow a strong IBD pattern, as observed in the Lesser Antilles (Guillot et al. 2005).

The cluster formed by Turneffe Atoll, Panama and Guadeloupe (and Martinique in the Geneland analysis) is unexpected, given the genetic and geographic distances among these locations, and the absence of specific water circulation patterns that might cause such a grouping. However, when analyses were repeated including only these sites, the sites divided into three separate clusters. This demonstrates the utility of repeating analyses on multisite clusters to uncover further patterns of population structure that are not revealed in the overall dataset analysis (Janes et al. 2017). The preliminary grouping of these sites may be partially due to size homoplasy in the microsatellites, which occurs when different alleles are identical lengths, and are consequently scored as the same allele-potentially creating spurious links (Estoup et al. 2002).

The sites in the United States formed a single cluster, comprising the Florida Keys sites and Gray's Reef National Marine Sanctuary, despite a distance of $\sim 770 \mathrm{~km}$ separating these areas, and the moderate $F_{\mathrm{ST}}$ and $D$ values. Although direct larval transport between the areas is very unlikely, indirect connectivity could be maintained via larval transportation in the Florida Current, coupled with 'stepping stones' of suitable coastal habitat harbouring intermediate populations along the south eastern coast of mainland USA. The USA cluster is probably distinct from the other Caribbean sites sampled due to distance rather than any particular oceanographic barrier; further fine-scale sampling of sites in the Greater Antilles and Gulf of Mexico would be required to explore this further.

\section{Population structure at smaller spatial scales}

The Mantel test indicated strong IBD within the Lesser Antilles (where distances between sites ranged 15-443 km). IBD is driven by distance-limited dispersal (Wright 1943; Aguillon et al. 2017), which is consistent with the short planktonic duration common for lecithotrophic sponge larvae. IBD patterns were also observed in the coral A. palmata in this area (Japaud et al. 2019), and have been found in other sponges at similar spatial scales elsewhere (Bell et al. 2014; Pérez-Portela et al. 2015; Riesgo et al. 2016). However, many sponge studies have found IBD to be absent or very weak, with oceanographic conditions forming better predictors of population structure (Giles et al. 2015; Taboada et al. 2018; Riesgo et al. 2019). This suggests that when oceanographic barriers are absent, limited larval dispersal in sponges can cause distance-decay relationships in genetic structuring.

In contrast, genetic IBD was not significant in the Florida Keys archipelago, where distances between sites ranged $10-115 \mathrm{~km}$. Pairwise genetic differentiation between sites in
Florida was relatively low (null allele-corrected $F_{\mathrm{ST}}$ ranged between 0.006 and 0.072), and the sites formed a single cluster in Geneland, PCoA and DAPC analyses. This suggests that larvae disperse across the area with sufficient regularity to maintain gene flow (although genetic similarity does not exclude the possibility of recent divergence). This result is interesting given the short larval duration and low dispersal capacity predicted for sponges, but concurs with other studies that show higher-than-expected levels of connectivity and dispersal (Chaves-Fonnegra et al. 2015; de Bakker et al. 2016). In other sponges, stronger genetic structure has been observed (e.g., Riesgo et al. 2019), most strikingly on spatial scales of centimetres to tens of metres in Crambe crambe and Scopalina lophyropoda (Calderón et al. 2007; Blanquer et al. 2009). This variation could be due to larval characteristics (Uriz et al. 2008); compared with other sponges, Irciniidae larvae are relatively strong swimmers with larger lipid stores (Ereskovsky and Tokina 2004; Mariani et al. 2006), theoretically aiding dispersal.

Although the Florida Keys formed a single genetic cluster, 8 out of 15 pairs of sites showed significant but low genetic differentiation, with no site consistently emerging as different from the rest-a common pattern in marine systems termed 'chaotic genetic patchiness' (Johnson and Black 1982). Chaotic genetic patchiness with weak or no IBD has also been found in other sponges across the Florida reef tract (DeBiasse et al. 2010; Chaves-Fonnegra et al. 2015; Richards et al. 2016), and in a co-occurring sponge, S. vesparium (Griffiths et al. 2020), which shared many sampling sites with this study.

Chaotic genetic patchiness can potentially result from a number of different processes (Eldon et al. 2016). One proposed cause is the random survival of larval cohorts due to stochastic oceanographic conditions, found in species with high fecundity and high larval mortality, termed 'sweepstakes reproductive success' (Hedgecock and Pudovkin 2011; Jolly et al. 2014). Another possible cause of temporal variation in recruitment and dispersal dynamics could be variability in local hydrodynamics across time (Schunter et al. 2019). Water circulation is highly variable among shallow, nearshore areas in Florida due to the predominance of wind-driven currents and storms regularly altering bathymetry. Asynchronicity in reproduction within populations could be a further component of temporal variability in recruitment dynamics (Eldon et al. 2016). Another possible cause is differential post-settlement selection (Norderhaug et al. 2016); in I. campana, this could result from high selection pressure exerted by cyanobacterial blooms (Butler et al. 1995) or disease (Maldonado et al. 2010). Indeed, we found evidence of a genetic bottleneck at Bamboo Key following a known mass mortality caused by a cyanobacterial bloom (see section below).

In Martinique, genetic differentiation was higher than expected between the two sampling sites $\left(F_{\mathrm{ST}}=0.063\right)$ 
considering their proximity $(15 \mathrm{~km})$. In addition, the DAPC and PCoA analyses highlighted genetic separation between the sites. Diamond Rock (MAR2) is a small island located $3 \mathrm{~km}$ off the Martinique coast. Both the island and the channel separating it from the mainland are locally known to experience strong currents (pers. comm. G. Tollu), and early modelling of water circulation suggests that the area may be influenced by a small gyre off the southern coast of Martinique (Lazure et al. 1996), which could reduce connectivity between the sites. However, more in-depth work on local water movement patterns is needed to further interpret the cause of this genetic differentiation.

\section{Genetic diversity and bottlenecks}

We found evidence of a genetic bottleneck in Bamboo Key, where previous mass mortalities were observed as part of widespread, reoccurring mass mortalities in sponge communities across the Florida Keys associated with cyanobacterial blooms (Butler et al. 1995; Stevely et al. 2010). This prompts concern for the population's resilience and adaptability to future stressors (Wernberg et al. 2018). Bottleneck signatures have also been found in other sponges in Mediterranean sites due to overharvesting (Pérez-Portela et al. 2015) and disease (Riesgo et al. 2016), underscoring the risks to genetic diversity levels for sponge populations that undergo significant declines. However, as null alleles can affect estimates of both heterozygosity and allelic richness, the possibility of a false positive at Bamboo Key cannot be excluded, given the presence of null alleles in our dataset.

Past mortalities also occurred in another of our sampling sites (Long Key in Florida), but a bottleneck signature was not detected here. This could be because any loss in genetic diversity was rapidly regained through recruitment and gene flow from other areas. Indeed, the Long Key site is dominated by long-shore currents, whereas the Bamboo Key site sits within a bay subject to a local gyre. Alternatively, it is possible that the Long Key result is a false negative, as heterozygosity excess tests are sensitive to mutation model selection and sample-size limitations (Garza and Williamson 2001; Peery et al. 2012). However, we found that genetic diversity was generally high in $I$. campana, with similar $H_{\mathrm{S}}$ ranges to other sponges (Chaves-Fonnegra et al. 2015; Giles et al. 2015; Richards et al. 2016; Riesgo et al. 2019); furthermore, allelic richness and $H_{\mathrm{S}}$ in Long Key were not significantly different from other sites.

Rapid population declines have not been reported in any of our other study sites, nor were significant bottleneck signatures detected. In addition, genetic diversity was largely similar across sites, with only Waltz Key and Turneffe Atoll showing significantly lower allelic richness than some Lesser Antilles sites (Mayreau, St. Lucia and Bequia). However, we did observe a disease-like condition in individuals harbouring necrosis of various stages in Guadeloupe and Bequia during sampling for this study, and on other occasions in Martinique (pers. obs. T. Pérez and S. Griffiths). Indeed, disease outbreaks and mass mortalities have been reported multiple times in Ircinia, often linked with higher temperatures (Perez et al. 2000; Maldonado et al. 2010; Stabili et al. 2012; Riesgo et al. 2016). Given this vulnerability, and the bottleneck signature found in Bamboo Key, continued genetic monitoring of $I$. campana would be prudent to ensure that bottlenecks are accurately identified for effective management of the species (Schwartz et al. 2007).

\section{Conservation implications}

Understanding the scale and magnitude of connectivity among populations is important for the management and conservation of marine ecosystems (Almany et al. 2009). Firstly, our results contribute to the increasing evidence suggesting that, for a number of taxa, the Sapodilla Cayes experiences low connectivity with other areas, and relies on high self-recruitment. This supports the current protection status for this area (the Sapodilla Cayes Marine Reserve), which is important to bolster the resilience of the population at this location, and to protect its unique genetic diversity. This study also implies that this population may form a separate management unit from other Belizean Marine Protected Areas (MPA); however, more extensive sampling of Belizean MPAs would be required to explore this further. More generally, our results tentatively suggest that to form connected MPAs for this species, protected areas would need to be situated within $\sim 50-100 \mathrm{~km}$ of each other, where suitable habitat exists and oceanographic barriers are absent. This would allow sufficient spillover of larvae to non-protected areas, and would maintain connectivity between protected areas.

Our results also provide insight for management of mass mortality-affected sites in Florida. Restoration through fragmenting and transplanting healthy sponges has been successfully used to repopulate barren areas (Butler et al. 2016). Our results suggest that gene flow occurs over the length of the Keys, indicating that donor sponges may be sourced from any area of the Keys without risk of outbreeding depression. Our results also indicate that connectivity over the area is unpredictable; therefore, restoration is supported as an important strategy to ensure rapid repopulation of mass mortality-affected areas. Genetic diversity is naturally high in I. campana populations; this should be maintained in restored sites through the use of a large number of donor sponges, rather than extensive fragmentation of few sponges.

\section{Data availability}

Microsatellite genotype data are available at https://doi.org/ 10.5061/dryad.gtht76hh7. 
Acknowledgements Permission to sample was granted from Panamá Ministerio de Ambiente (SC/A-36-16), Belize Fisheries Department (000023-13 and 000010-14), US Department of the Interior National Park Service (Everglades) (EVER-2014-SCI-0050), Florida Fish and Wildlife Commission (SAL-13-0582A-SR), NOAA (GRNMS-2010-001) and all the agencies involved in granting permission to the PACOTILLES campaign (FAUVELOT Cécile (2015) PACOTILLES-1 cruise, RV Antea, 10.17600/15005200; PEREZ Thierry (2015) PACOTILLES-2 cruise, RV Antea, 10.17600/15005300). We would like to thank the PACOTILLES campaign team and crew of the RV Antea, M. Madrid, R. Payne, F. Clever, C. Freeman, T. Allen, P. Alford, ReefCI (Placencia), Frenchies (Caye Caulker), Scuba Sensations (Caye Caulker), La Buga (Bocas del Toro) and students from University of Florida and Old Dominion University for sampling assistance. Thanks to G. Tollu (Impact Mer) for advice on local currents around Martinique. This was funded by a Natural Environment Research Council (NERC) PhD studentship awarded to SMG, ship time from Flotte Océanographique Française awarded to TP and C. Fauvelot, a grant from the Nature Conservancy and NOAACommunity Restoration Partnership to MJB and DCB.

\section{Compliance with ethical standards}

Conflict of interest The authors declare that they have no conflict of interest.

Publisher's note Springer Nature remains neutral with regard to jurisdictional claims in published maps and institutional affiliations.

Open Access This article is licensed under a Creative Commons Attribution 4.0 International License, which permits use, sharing, adaptation, distribution and reproduction in any medium or format, as long as you give appropriate credit to the original author(s) and the source, provide a link to the Creative Commons license, and indicate if changes were made. The images or other third party material in this article are included in the article's Creative Commons license, unless indicated otherwise in a credit line to the material. If material is not included in the article's Creative Commons license and your intended use is not permitted by statutory regulation or exceeds the permitted use, you will need to obtain permission directly from the copyright holder. To view a copy of this license, visit http://creativecommons. org/licenses/by/4.0/.

\section{References}

Addison JA, Hart MW (2005) Spawning, copulation and inbreeding coefficients in marine invertebrates. Biol Lett 1:450-453

Aguillon SM, Fitzpatrick JW, Bowman R, Schoech SJ, Clark AG, Coop $G$ et al. (2017) Deconstructing isolation-by-distance: the genomic consequences of limited dispersal. PLoS Genet 13:1-27

Almany GR, Connolly SR, Heath DD, Hogan JD, Jones GP, McCook LJ et al. (2009) Connectivity, biodiversity conservation and the design of marine reserve networks for coral reefs. Coral Reefs 28:339-351

Bates D, Mächler M, Bolke B, Walker S (2015) Fitting linear mixedeffects models using lme4. J Stat Softw 67:1-48

Baums IB (2008) A restoration genetics guide for coral reef conservation. Mol Ecol 17:2796-2811

Bell JJ, Smith D, Hannan D, Haris A, Jompa J, Thomas L (2014) Resilience to disturbance despite limited dispersal and selfrecruitment in tropical barrel sponges: implications for conservation and management. PLoS ONE 9:e91635

Benjamini Y, Yekutieli D (2001) The control of the false discovery rate in multiple testing under dependency. Ann Stat 29: $1165-1188$
Bertelsen RD, Butler MJ, Herrnkind WF, Hunt JH (2009) Regional characterisation of hard-bottom nursery habitat for juvenile Caribbean spiny lobster (Panulirus argus) using rapid assessment techniques. N. Zeal J Mar Freshw Res 43:299-312

Blanquer A, Uriz M, Caujapé-Castells J (2009) Small-scale spatial genetic structure in Scopalina lophyropoda, an encrusting sponge with philopatric larval dispersal and frequent fission and fusion events. Mar Ecol Prog Ser 380:95-102

Butler MJ, Hunt JH, Herrnkind WF, Childress MJ, Bertelsen R, Sharp $\mathrm{W}$ et al. (1995) Cascading disturbances in Florida Bay, USA: cyanobacteria blooms, sponge mortality, and implications for juvenile spiny lobsters Panulirus argus. Mar Ecol Prog Ser 129:119-125

Butler J, Stanley JA, Butler MJ (2016) Underwater soundscapes in near-shore tropical habitats and the effects of environmental degradation and habitat restoration. J Exp Mar Bio Ecol 479:89-96

Butler IV MJ, Behringer DC, Valentine MM (2017) Commercial sponge fishery impacts on the population dynamics of sponges in the Florida Keys, FL (USA). Fish Res 190:113-121

Calderón I, Ortega N, Duran S, Becerro M, Pascual M, Turon X (2007) Finding the relevant scale: clonality and genetic structure in a marine invertebrate (Crambe crambe, Porifera). Mol Ecol 16:1799-1810

Carrillo L, Johns EM, Smith RH, Lamkin JT, Largier JL (2015) Pathways and hydrography in the Mesoamerican Barrier Reef System Part 1: Circulation. Cont Shelf Res 109:164-176

Castorani MCN, Reed DC, Raimondi PT, Alberto F, Bell TW, Cavanaugh KC et al. (2017) Fluctuations in population fecundity drive variation in demographic connectivity and metapopulation dynamics. Proc R Soc B Biol Sci 284:20162086.

Chapuis M-P, Estoup A (2007) Microsatellite null alleles and estimation of population differentiation. Mol Biol Evol 24:621-31

Chaves-Fonnegra A, Feldheim KA, Secord J, Lopez JV (2015) Population structure and dispersal of the coral-excavating sponge Cliona delitrix. Mol Ecol 24:1447-66

Chybicki IJ, Burczyk J (2009) Simultaneous estimation of null alleles and inbreeding coefficients. J Hered 100:106-13

D'Aloia CC, Bogdanowicz SM, Harrison RG, Buston PM (2017) Cryptic genetic diversity and spatial patterns of admixture within Belizean marine reserves. Conserv Genet 18:211-223

Dailianis T, Tsigenopoulos CS, Dounas C, Voultsiadou E (2011) Genetic diversity of the imperilled bath sponge Spongia officinalis Linnaeus, 1759 across the Mediterranean Sea: patterns of population differentiation and implications for taxonomy and conservation. Mol Ecol 20:3757-72

de Bakker DM, Meesters EHWG, van Bleijswijk JDL, Luttikhuizen PC, Breeuwer HJAJ, Becking LE (2016) Population genetic structure, abundance, and health status of two dominant benthic species in the Saba Bank National Park, Caribbean Netherlands: Montastraea cavernosa and Xestospongia muta. PLoS ONE 11: e0155969

DeBiasse MB, Richards VP, Shivji MS (2010) Genetic assessment of connectivity in the common reef sponge, Callyspongia vaginalis (Demospongiae: Haplosclerida) reveals high population structure along the Florida reef tract. Coral Reefs 29:47-55

DeBiasse MB, Richards VP, Shivji MS, Hellberg ME (2016) Shared phylogeographical breaks in a Caribbean coral reef sponge and its invertebrate commensals. J Biogeogr 43:2136-2146

Dempster AP, Laird NM, Rubin DB (1977) Maximum likelihood from incomplete data via the EM algorithm. J R Stat Soc Ser B 39:1-38

Diaz M, Rutzler K (2001) Sponges: an essential component of Caribbean coral reefs. Bull Mar Sci 69:535-546

Drury C, Paris CB, Kourafalou VH, Lirman D (2018) Dispersal capacity and genetic relatedness in Acropora cervicornis on the Florida Reef Tract. Coral Reefs 37:585-596 
Eldon B, Riquet F, Yearsley J, Jollivet D, Broquet T (2016) Current hypotheses to explain genetic chaos under the sea. Curr Zool 62:551-566

Ereskovsky AV, Tokina DB (2004) Morphology and fine structure of the swimming larvae of Ircinia oros (Porifera, Demospongiae, Dictyoceratida). Invertebr Reprod Dev 45:137-150

Estoup A, Jarne P, Cornuet J-M (2002) Homoplasy and mutation model at microsatellite loci and their consequences for population genetics analysis. Mol Ecol 11:1591-1604

Ezer T, Thattai DV, Kjerfve B, Heyman WD (2005) On the variability of the flow along the Meso-American Barrier Reef system: A numerical model study of the influence of the Caribbean current and eddies. Ocean Dyn 55:458-475

Foster NL, Paris CB, Kool JT, Baums IB, Stevens JR, Sanchez JA et al. (2012) Connectivity of Caribbean coral populations: complementary insights from empirical and modelled gene flow. Mol Ecol 21:1143-1157

Garza JC, Williamson EG (2001) Detection of reduction in population size using data from microsatellite loci. Mol Ecol 10:305-18

Giles EC, Saenz-Agudelo P, Hussey NE, Ravasi T, Berumen ML (2015) Exploring seascape genetics and kinship in the reef sponge Stylissa carteri in the Red Sea. Ecol Evol 5:2487-502

Griffiths SM, Antwis RE, Lenzi L, Lucaci A, Behringer DC, Butler MJ et al. (2019) Host genetics and geography influence microbiome composition in the sponge Ircinia campana. J Anim Ecol 88:1984-1695

Griffiths SM, Taylor-Cox ED, Behringer DC, Butler MJ, Preziosi RF (2020) Using genetics to inform restoration and predict resilience in declining populations of a keystone marine sponge. Biodivers Conserv 29:1383-1410

Guardiola M, Frotscher J, Uriz M-J (2016) High genetic diversity, phenotypic plasticity, and invasive potential of a recently introduced calcareous sponge, fast spreading across the AtlantoMediterranean basin. Mar Biol 163:123

Guillot G, Estoup A, Mortier F, Cosson JF (2005) A spatial statistical model for landscape genetics. Genetics 170:1261-1280

Guillot G, Santos F, Estoup A (2008) Analysing georeferenced population genetics data with Geneland: a new algorithm to deal with null alleles and a friendly graphical user interface. Bioinformatics 24:1406-1407

Hedgecock D, Pudovkin AI (2011) Sweepstakes reproductive success in highly fecund marine fish and shellfish: a review and commentary. Bull Mar Sci 87:971-1002

Herrnkind WF, Butler IV MJ, Hunt JH, Childress M (1997) Role of physical refugia: implications from a mass sponge die-off in a lobster nursery in Florida. Mar Freshw Res 48:759

Hoffman JI, Peck LS, Linse K, Clarke A (2011) Strong population genetic structure in a broadcast-spawning Antarctic marine invertebrate. J Hered 102:55-66

Hothorn T, Bretz F, Westfall P (2008) Simultaneous inference in general parametric models. Biometrical J 50:346-363

Janes JK, Miller JM, Dupuis JR, Malenfant RM, Gorrell JC, Cullingham CI et al. (2017) The $K=2$ conundrum. Mol Ecol 26:3594-3602

Japaud A, Bouchon C, Magalon H, Fauvelot C (2019) Geographic distances and ocean currents influence Caribbean Acropora palmata population connectivity in the Lesser Antilles. Conserv Genet 20:447-466

Johnson MS, Black R (1982) Chaotic genetic patchiness in an intertidal limpet, Siphonaria sp. Mar Biol 70:157-164

Jolly MT, Thiébaut E, Guyard P, Gentil F, Jollivet D (2014) Mesoscale hydrodynamic and reproductive asynchrony affects the source-sink metapopulation structure of the coastal polychaete Pectinaria koreni. Mar Biol 161:367-382

Jombart T (2008) Adegenet: A R package for the multivariate analysis of genetic markers. Bioinformatics 24:1403-1405
Jombart T, Devillard S, Balloux F (2010) Discriminant analysis of principal components: a new method for the analysis of genetically structured populations. BMC Genet 11:94

Jost L (2008) $G_{\mathrm{ST}}$ and its relatives do not measure differentiation. Mol Ecol 17:4015-4026

Knutsen H, Jorde PE, Andre C, Stenseth NC (2003) Fine-scaled geographical population structuring in a highly mobile marine species: the Atlantic cod. Mol Ecol 12:385-394

Lazure P, Salomon JC, Breton M (1996) Subtidal circulation in Fortde-France Bay. In: Maul GA (ed) Small Islands: Marine Science and Sustainable Development, Volume 51. American Geophysical Union, Washington DC

López-Legentil S, Pawlik JR (2009) Genetic structure of the Caribbean giant barrel sponge Xestospongia muta using the I3-M11 partition of COI. Coral Reefs 28:157-165

Maebe K, Golsteyn L, Nunes-Silva P, Blochtein B, Smagghe G (2018) Temporal changes in genetic variability in three bumblebee species from Rio Grande do Sul, South Brazil. Apidologie 49:415-429

Maldonado M, Riesgo A (2008) Reproduction in Porifera: a synoptic overview. Treb la SCB 59:29-49

Maldonado M, Sánchez-Tocino L, Navarro C (2010) Recurrent disease outbreaks in corneous demosponges of the genus Ircinia: Epidemic incidence and defense mechanisms. Mar Biol 157:1577-1590

Maldonado M, Uriz M (1999) Sexual propagation by sponge fragments. Nature 398:1999

Mariani S, Uriz MJ, Turon X, Alcoverro T (2006) Dispersal strategies in sponge larvae: Integrating the life history of larvae and the hydrologic component. Oecologia 149:174-184

Martínez S, Carrillo L, Marinone SG (2019) Potential connectivity between marine protected areas in the Mesoamerican Reef for two species of virtual fish larvae: Lutjanus analis and Epinephelus striatus. Ecol Indic 102:10-20

Meirmans PG, Van Tienderen PH (2004) Genotype and Genodive: two programs for the analysis of genetic diversity of asexual organisms. Mol Ecol Notes 4:792-794

Morin PA, Leduc RG, Archer FI, Martien KK, Huebinger R, Bickham JW et al. (2009) Significant deviations from Hardy-Weinberg equilibrium caused by low levels of microsatellite genotyping errors. Mol Ecol Resour 9:498-504

Muhling BA, Smith RH, Vásquez-Yeomans L, Lamkin JT, Johns EM, Carrillo L et al. (2013) Larval fish assemblages and mesoscale oceanographic structure along the Mesoamerican Barrier Reef System. Fish Oceanogr 22:409-428

Norderhaug KM, Anglès d'Auriac MB, Fagerli CW, Gundersen H, Christie H, Dahl K et al. (2016) Genetic diversity of the NE Atlantic sea urchin Strongylocentrotus droebachiensis unveils chaotic genetic patchiness possibly linked to local selective pressure. Mar Biol 163:1-13

Pante E, Simon-Bouhet B (2013) marmap: a package for importing, plotting and analyzing bathymetric and topographic data in R. PLoS One 8:e73051

Peakall R, Smouse PE (2012) GenAlEx 6.5: genetic analysis in Excel. Population genetic software for teaching and research- an update. Bioinformatics 28:2537-2539

Peery MZ, Kirby R, Reid BN, Stoelting R, Douchet-Beer E, Robinson $S$ et al. (2012) Reliability of genetic bottleneck tests for detecting recent population declines. Mol Ecol 21:3403-3418

Pérez-Portela R, Noyer C, Becerro MA (2015) Genetic structure and diversity of the endangered bath sponge Spongia lamella. Aquat Conserv Mar Freshw Ecosyst 25:365-379

Perez T, Garrabou J, Sartoretto S, Harmelin JG, Francour P, Vacelet J (2000) Massive mortality of marine invertebrates: an unprecedented event in northwestern Mediterranean. C R Acad Sci III 323:853-65 
Piry S, Luikart G, Cornuet J-M (1999) Computer note. BOTTLENECK: a computer program for detecting recent reductions in the effective size using allele frequency data. J Hered 90:502-503

R Core Team (2017) R: A language and environment for statistical computing. R Foundation for Statistical Computing, Vienna, Austria. URL https://www.R-project.org/

Raymond M, Rousset F (1995) GENEPOP (Version 1.2): population genetics software for exact tests and ecumenicism. J Hered 86:248-249

Richards VP, Bernard AM, Feldheim KA, Shivji MS (2016) Patterns of population structure and dispersal in the long-lived "redwood" of the coral reef, the giant barrel sponge (Xestospongia muta). Coral Reefs 35:1097-1107

Riesgo A, Pérez-Portela R, Pita L, Blasco G, Erwin PM, LópezLegentil S (2016) Population structure and connectivity in the Mediterranean sponge Ircinia fasciculata are affected by mass mortalities and hybridization. Heredity 117:427-439

Riesgo A, Taboada S, Pérez-Portela R, Melis P, Xavier JR, Blasco G et al. (2019) Genetic diversity, connectivity and gene flow along the distribution of the emblematic Atlanto-Mediterranean sponge Petrosia ficiformis (Haplosclerida, Demospongiae). BMC Evol Biol 19:1-18

Rippe JP, Matz MV, Green EA, Medina M, Khawaja NZ, Pongwarin $T$ et al. (2017) Population structure and connectivity of the mountainous star coral, Orbicella faveolata, throughout the wider Caribbean region. Ecol Evol 7:9234-9246

Rosenberg NA (2004) DISTRUCT: a program for the graphical display of population structure. Mol Ecol Notes 4:137-138

Schunter C, Pascual M, Raventos N, Garriga J, Garza JC, Bartumeus F et al. (2019) A novel integrative approach elucidates fine-scale dispersal patchiness in marine populations. Sci Rep 9:1-10

Schwartz MK, Luikart G, Waples RS (2007) Genetic monitoring as a promising tool for conservation and management. Trends Ecol Evol 22:25-33

Shanks AL (2009) Pelagic larval duration and dispersal distance revisited. Biol Bull 216:373-85

Siegel DA, Mitarai S, Costello CJ, Gaines SD, Kendall BE, Warner RR et al. (2008) The stochastic nature of larval connectivity among nearshore marine populations. Proc Natl Acad Sci 105:8974-9

Sole-Cava AM, Klautau M, Boury-Esnault N, Borojecic R, Thorpe JP (1991) Genetic evidence for cryptic speciation in allopatric populations of two cosmopolitan species of the calcareous sponge genus Clathrina. Mar Biol 111:381-386

Soro A, Quezada-Euan JJG, Theodorou P, Moritz RFA, Paxton RJ (2017) The population genetics of two orchid bees suggests high dispersal, low diploid male production and only an effect of island isolation in lowering genetic diversity. Conserv Genet 18:607-619

Soto I, Andréfouët S, Hu C, Muller-Karger FE, Wall CC, Sheng J et al. (2009) Physical connectivity in the Mesoamerican Barrier Reef
System inferred from 9 years of ocean color observations. Coral Reefs 28:415-425

Stabili L, Cardone F, Alifano P, Tredici SM, Piraino S, Corriero G et al. (2012) Epidemic mortality of the sponge Ircinia variabilis (Schmidt, 1862) associated to proliferation of a Vibrio bacterium. Micro Ecol 64:802-813

Stevely JM, Sweat DE, Bert TM, Sim-Smith C, Kelly M (2010) Sponge mortality at Marathon and Long Key, Florida: patterns of species response and population recovery. Proc 63rd Gulf Caribb Fish Inst 63:384-400

Szpiech ZA, Jakobsson M, Rosenberg NA (2008) ADZE: a rarefaction approach for counting alleles private to combinations of populations. Bioinformatics 24:2498-2504

Taboada S, Riesgo A, Wiklund H, Paterson GLJ, Koutsouveli V, Santodomingo N et al. (2018) Implications of population connectivity studies for the design of marine protected areas in the deep sea: an example of a demosponge from the ClarionClipperton Zone. Mol Ecol 27:4657-4679

Tesson SVM, Montresor M, Procaccini G, Kooistra WHCF (2014) Temporal changes in population structure of a marine planktonic diatom. PLoS One 9:e114984

Truelove NK, Griffiths S, Ley-Cooper K, Azueta J, Majil I, Box SJ et al. (2014) Genetic evidence from the spiny lobster fishery supports international cooperation among Central American marine protected areas. Conserv Genet 16:347-358

Uriz MJ, Turon X, Mariani S (2008) Ultrastructure and dispersal potential of sponge larvae: tufted versus evenly ciliated parenchymellae. Mar Ecol 29:280-297

Vacelet J (1999) Planktonic armoured propagules of the excavating sponge Alectona (Porifera: Demospongiae) are larvae: evidence from Alectona wallichii and A. mesatlantica sp. nov. Mem Queensl Mus 44:627-642

Vaha J-P, Erkinaro J, Niemela E, Primmer CR (2007) Life-history and habitat features influence the within-river genetic structure of Atlantic salmon. Mol Ecol 16:2638-2654

Valentine MM, Butler MJ IV (2019) Sponges structure water-column characteristics in shallow tropical coastal ecosystems. Mar Ecol Prog Ser 608:133-147

Wernberg T, Coleman MA, Bennett S, Thomsen MS, Tuya F, Kelaher BP (2018) Genetic diversity and kelp forest vulnerability to climatic stress. Sci Rep 8:1851

Wright S (1943) Isolation by distance. Genetics 28:114-38

Wulff JL (1991) Asexual fragmentation, genotype success, and population dynamics of erect branching sponges. J Exp Mar Bio Ecol 149:227-247

Wulff J (2006) Rapid diversity and abundance decline in a Caribbean coral reef sponge community. Biol Conserv 127:167-176

Xavier JR, Rachello-Dolmen PG, Parra-Velandia F, Schönberg CHL, Breeuwer JAJ, van Soest RWM (2010) Molecular evidence of cryptic speciation in the 'cosmopolitan' excavating sponge Cliona celata (Porifera, Clionaidae). Mol Phylogenet Evol $56: 13-20$ 